\title{
REFLEXÕES SOBRE DIREITO AO ENSINO DOMICILIAR
}

\author{
Maria Lucia Sucupira Medeiros e Stella Regina Taquette \\ 1.2Universidade do Estado do Rio de Janeiro, UERJ, Brasil. mlsucupira@gmail.com, stella.taquette@gmail.com
}

\begin{abstract}
Resumo. $O$ ensino oficial nos estabelecimentos educacionais tradicionais brasileiros tem sido alvo de críticas quanto à sua qualidade e abrangência. Diante disso, o ensino domiciliar se apresenta como alternativa viável e inserida no direito constitucional de liberdade. Contudo, pela ausência de legislação específica, as famílias que a adotam têm sido consideradas à margem da lei. Diante desse fato, a investigação objetiva estudar diferentes visões científicas de pesquisadores das áreas da Educação e do Direito sobre a educação e o ensino domiciliar. O processo metodológico que orienta essas reflexões iniciais baseia-se no estudo bibliográfico de artigos de pesquisa indexados no SciELO e de livros de autores consagrados como Philippe Ariès; Diniz \& Guilhem; Serodio, Kopelman, \& Bataglia, entre outros. Os resultados inicialmente obtidos pela referida pesquisa dão conta de que existe uma gama de posições divergentes, à medida que a falta de regulamentação do ensino domiciliar afronta os direitos de liberdade, do pluralismo de ideias e de concepções pedagógicas previstos na Constituição vigente, a qual não proíbe, expressamente, essa modalidade de ensino. Conclui-se ser preciso investigar o homeschooling à luz dessas reflexões, a fim de encontrar um resultado que aborde seu impacto no desenvolvimento e socialização de crianças e adolescentes.
\end{abstract}

Palavras-chave: Educação; Direito; Bioética Principialista; Estatuto da Criança e do Adolescente; Homeschooling.

\section{REFLECTIONS ON THE RIGHT TO HOME SCHOOLING}

Abstract. The official education in traditional Brazilian establishments has been the target of criticism regarding its quality and scope. Therefore, homeschooling is a viable alternative and inserted in the constitutional right of freedom. Due to the absence of specific legislation, the families that adopt it have been considered outside the law. Thus, the present investigation aims to study different scientific views of researchers on Education and Law about homeschooling. The methodology that will guide these initial reflections is based on the bibliographic study of research articles indexed in SciELO and books by renowned authors such as Philippe Ariès; Diniz \& Guilhem; Serodio, Kopelman, \& Bataglia, among others. The results obtained so far by the aforementioned research show that there is a range of divergent positions, insofar as the lack of regulation of home education affronts the rights of freedom and the pluralism of ideas and pedagogical concepts provided for in the current Constitution, which does not expressly prohibit this type of teaching. It is opportune to conclude that it is necessary to investigate homeschooling in the light of these reflections, in order to find a result that addresses its impact on the development and socialization of children and adolescents.

Keywords: Education; Right; Principialist Bioethics; Child and Adolescent Statute; Homeschooling.

\section{INTRODUÇÃO}

Neste trabalho, evidencia-se a necessidade de haver uma investigação aprofundada sobre os benefícios e malefícios da educação domiciliar, assim como entender o limite da autonomia privada na escolha dessa metodologia de ensino, consistindo na liberdade dos pais para viabilizar a melhor educação de seus filhos e a proteção prevista no Estatuto da Criança e do Adolescente (ECA). Leva-se em conta o sentido de justiça ou não da escolha, a ser traduzida na proteção e fiscalização do Estado a essa classe vulnerável da sociedade. 
Por outro lado, verifica-se haver intolerância no reconhecimento da pluralidade de ideias e concepções pedagógicas, quando ainda não se permite no Brasil o ensino domiciliar. Tal interdição se encaixa no pretenso estudo que visa a buscar o reconhecimento da pluralidade moral existente em diferentes culturas e religiões que porventura cercam o ensino domiciliar. Não se pode desprezar, porém, que o ser humano precisa se orientar por regras que viabilizem o bem-estar do convívio social, as quais, muitas vezes, podem tolher seu comportamento em determinadas áreas.

Com base no princípio de não interferência estatal em que se encaixa o homeschooling, modalidade de ensino fora da escola, a parte relativa à instrução formal e acadêmica é assumida pelos responsáveis, incluindo costumes, hábitos, moral e crenças.

\section{FUNDAMENTAÇÃO TEÓRICA}

A Constituição Federal de 1988 considera a educação direito fundamental de todos e dever do Estado e da família, a ser promovida e incentivada com a colaboração da sociedade, visando ao pleno desenvolvimento da pessoa, seu preparo para o exercício da cidadania e sua qualificação para o trabalho. Porém, a Constituição e qualquer outro diploma legal não proíbem expressamente o ensino domiciliar, pois sequer fazem menção a esse tipo de educação fora da escola tradicional, seja ela privada ou pública, deixando a impressão, em clara prova, de sua aplicação não estar proibida.

Com base em princípios constitucionais voltados para a obrigatoriedade da educação como um dos direitos do cidadão, o ensino domiciliar, denominado homeschooling, inicialmente experimentado nos Estados Unidos da América, se apresenta como realidade para milhares de famílias que pretendem educar seus filhos em casa. Sua prática dispõe de um elenco de argumentos defensáveis, baseados em diversas alegações, todas, porém, com o mesmo fim: provar a insuficiência qualitativa e quantitativa do ensino público e de seu oferecimento pelo Estado; pouco conhecimento sobre o tema por parte da sociedade; reivindicação de autonomia e liberdade frente à Constituição Federal; direito de se exigir a execução de políticas públicas voltadas para a educação.

À luz dos preceitos constitucionais e da perspectiva doutrinária de diversos filósofos, juristas e educadores que lidam cotidianamente nestas esferas, a educação deve ser acessível a todos enquanto direito fundamental, humano e social, independentemente de 
ser obrigatória em estabelecimentos oficiais de ensino. Vale ressaltar que a educação de crianças e adolescentes tem impacto no desenvolvimento físico e emocional desses seres.

Ao serem impostos ao ensino domiciliar ficam privados da socialização com seus pares que do ponto de vista da saúde é essencial para garantir a aquisição de aptidões necessárias para uma vida saudável (Halpern, 2015, p. 8). Além do mais, quando se observam os princípios concernentes à bioética, consegue-se perceber que o trato de assuntos da saúde, os quais representam quase a unanimidade, se assemelha ao enfoque dos assuntos pertinentes à educação, ambos traduzidos como direito fundamental do indivíduo, haja vista sua universalidade: "o alinhamento bioético-medicina não é caraterística exclusiva do Brasil, sendo, na verdade, um fato comum à grande maioria dos países onde a bioética vem se consolidando" (Diniz \& Guilhem, 2002, p. 73).

Ao longo da história, a tradição de aprender uns com os outros e de transmitir conhecimentos e culturas acumulados nas gerações sempre esteve presente em qualquer agrupamento social. Tal processo pode ser considerado como inerente à própria natureza humana e como elemento essencial para a manutenção da espécie (Borges, 2019, p. 2-3). Entretanto, não se pode ficar alheio aos impactos que a globalização vem exercendo sobre a educação, a qual passa a ser considerada, nesse contexto, como mercadoria. Também há de se levar em conta, além da perspectiva filosófica de sua presença na Carta Magna de 1988, a constatação de ser a educação vital para a formação da cidadania e da própria dignidade da pessoa humana.

Diante desse cenário, a tarefa do Direito se entrelaça com os princípios da Bioética, quando se propõe a definir regras de conduta no sentido de conciliar a liberdade individual com a convivência do grupo, possibilitando o acesso de todos os cidadãos aos recursos disponíveis na sociedade.

Para alcançar esse equilíbrio, torna-se necessário levar em conta as aspirações de cada um e the possibilitar o desenvolvimento de suas aptidões, preservando a personalidade da pessoa humana, aqui entendida como substrato da sociedade. Numa democracia que se quer humanista, respeitar a individualidade da pessoa humana em confronto com a sociedade em que esteja inserida talvez seja o único princípio coerente com sua dignidade. "É esta a razão pela qual as descobertas biomédicas devem sempre ser analisadas em 
função da ótica dos Direitos Fundamentais, face à necessidade de equilíbrio entre a vida humana, a moral e os direitos do cidadão" (Pereira, 2020, p. 45).

Fora o exposto até aqui, não há proibição expressa quanto ao ensino domiciliar, mas sim uma lacuna jurídica. O artigo 229, da Constituição Federal de 1988, dirige aos pais a assistência, criação e educação de seus filhos, quando afirma que "os pais têm o dever de assistir, criar e educar os filhos menores", embasando, assim, a escolha lícita pela educação domiciliar, segundo os pais que já a praticam (Brasil, 2019, p. 228). "Lamentavelmente, o que está acontecendo é o descompasso da evolução das normas jurídicas em acompanhar o desenvolvimento da ciência médica" (Sá, 1998, p. 13), tal como ocorre no caso da educação domiciliar.

Susana Gavassi (2019, p. 5) endossa as opiniões de dois estudiosos sobre a infância. No primeiro caso, o historiador francês Philippe Ariès mostra que somente "a partir do século XVII a classe burguesa europeia passa a perceber a existência da criança como um ser diferenciado, frágil, e que necessitava de cuidados físicos e morais" (Ariès, 1981, p. 105). Surgia, assim, o sentimento de família. O segundo caso manifesta que "a ideia de infância tem significados próprios a cada época e contexto social, haja vista que são compreendidos de formas diferenciadas, influenciados por questões culturais, filosóficas, econômicas e religiosas" (Heywood, 2004, p. 12).

Além disso, a autora manifesta a diferença entre os conceitos de criança e menor, tal como concebida por Ariès, nos seguintes termos: "Criança passa a ser o termo designado aos filhos da classe burguesa, refletindo o que já havia na Europa: 'o sentimento de infância será diferente entre os filhos da classe burguesa e os filhos da classe trabalhadora' (Ariès, 1981, p. 150)".

O ECA foi criado com intuito de proteger integralmente o menor conforme previsto em seus artigos $1^{\circ}$ e $2^{\circ}$, com a definição de criança e adolescente nos seguintes artigos: "Art. $1^{\circ}$ Esta Lei dispõe sobre a proteção integral à criança e ao adolescente. Art. $2^{\circ}$ Considera-se criança, para os efeitos desta Lei, a pessoa até doze anos de idade incompletos, e adolescente aquela entre doze e dezoito anos de idade" (Brasil, 2019, p. 10). Com relação ao disposto, Susana Gavassi sustenta que a intenção dos legisladores era de a direção das escolas auxiliar a proteger as crianças vítimas de maus-tratos no ambiente familiar, bem como garantir seu acesso à escolarização. 
Entretanto, há casos em que a direção das escolas deixa de realizar a comunicação, por temer conflitos com os pais e/ou responsáveis das crianças. A mesma autora acrescenta o seguinte comentário:

Todas estas medidas sinalizam que a escola tem que se adaptar à nova Lei para tornar-se parte integrante na Rede de Proteção à Infância e Adolescência. Contudo, na prática, o que se nota é que a maioria de nossas escolas ainda não está integrada à rede de proteção. Pelo contrário, parecem andar na contramão do que preconiza o Estatuto, na medida em que o responsabilizam pelo agravamento dos problemas enfrentados em seu cotidiano como a indisciplina escola (Gavassi, 2019, p. 11).

\section{OBJETIVOS}

O objetivo principal desse trabalho acadêmico é analisar a percepção dos educadores públicos e privados sobre o ensino domiciliar a luz da Bioética Principialista e os benefícios ou malefícios que podem advir, caso seja aprovado pelo Legislativo.

Os objetivos específicos são identificar benefícios e malefícios do ensino domiciliar; verificar os limites da liberdade e da autonomia da família no ensino domiciliar; pesquisar o interesse coletivo versus interesse privado no ensino domiciliar; verificar se o Estatuto da Criança e do Adolescente (ECA) protege o educando, tal qual expresso na Constituição Federal de 1988 e no próprio Estatuto.

\section{METODOLOGIA}

O artigo propõe estudar, mediante investigação bibliográfica e pesquisa de campo, quais são os benefícios, os malefícios e o limite da autonomia privada para o ensino domiciliar. Em outra esfera, se aborda se existe justiça ou não na aplicação desse modelo de ensino que, diferente dos modelos tradicionais propostos pelas leis em vigor, envolve a liberdade de escolha resultante do pluralismo de ideias e de concepções pedagógicas, implicando também a convivência virtuosa com as instituições públicas e privadas de ensino.

O presente trabalho acadêmico adotará a pesquisa qualitativa como método a ser aplicado, tendo em vista que pretende analisar os significados que não são percebidos exclusivamente por aspectos quantitativos. O homeschooling é tema propício para a abordagem mediante a pesquisa qualitativa, principalmente quando se verifica que existem inúmeras realidades em torno das questões a serem enfocadas, as quais nem sempre trazem seus significados visíveis. 


\subsection{Coleta de dados}

Busca-se investigar estudos já realizados e publicados sobre a temática homeschooling e a percepção individual de pesquisadores doutores das áreas da Educação e do Direito que atuam em Instituições de Ensino Superior brasileiras sobre o ensino domiciliar (homeschooling), a fim de se verificarem a concepção e a análise destes profissionais a respeito da autonomia privada das famílias na educação de seus filhos, de acordo com os objetivos mencionados acima. O estudo bibliográfico será realizado por meio de busca de artigos na base de dados Scientific Electronic Library Online (SciELO) do Brasil, principal base de periódicos científicos brasileiros, cujos artigos aceitos para publicação são avaliados por pares com critérios previamente estabelecidos e reconhecidos como válidos pela comunidade científica. Será utilizado o descritor "ensino domiciliar".

O estudo de campo será desenvolvido por meio de entrevistas em profundidade com os profissionais mencionados acima, pesquisadores da área da Educação e do Direito de Instituições de Ensino Superior públicas e privadas. Pretende-se entrevistar cerca de 10 pesquisadores de cada área, com amostra total prevista de 20 entrevistados. A amostra poderá ser ampliada, caso não se alcance a saturação dos conteúdos.

Após contato da pesquisadora, a participação destes profissionais será voluntária, não remunerada, não implicará gastos pessoais e se dará por meio de entrevista. Os dados colhidos nas entrevistas com professores de Educação e de Direito serão consolidados e se constituirão em fonte de pesquisa significativa na construção de massa crítica para o presente estudo, que vai envolver também as normas existentes sobre educação, os dados colhidos durante a leitura dos artigos científicos que abordam a educação e o homeschooling. Para se angariar a opinião mais relevante possível, os entrevistados serão selecionados por meio da Plataforma Lattes do Conselho Nacional de Desenvolvimento Científico e Tecnológico (CNPq), tendo em vista sua atuação nas áreas mencionadas.

As entrevistas seguirão roteiro contendo duas partes, sendo a primeira com dados sociodemográficos e de experiência profissional, e a segunda a respeito do homeschooling, ou seja, tópicos referentes ao dever do Estado na educação, à competência e à autonomia da família para o ensino domiciliar e ao desenvolvimento e socialização da criança. Serão desenvolvidas em ambiente com privacidade e garantia de sigilo e confidencialidade após consentimento informado. As atividades previstas não apresentam riscos significativos, entretanto, caso o participante sinta algum desconforto, elas poderão ser interrompidas a 
qualquer momento. Nestas entrevistas aparecerá o valor ético para saber se o homeschooling será adequado ou não para o Brasil. Se, depois de haver consentido e concordado com a pesquisa, o participante preferir desistir, tem assegurados o direito e a liberdade de retirar seu consentimento em qualquer das etapas, independentemente do motivo e sem nenhum prejuízo para sua pessoa.

O registro das entrevistas será feito por meio de gravação digital e transcritas na íntegra. Os responsáveis pela investigação se comprometem a tornar públicos os resultados analisados, inclusive de forma consolidada, nos meios acadêmicos e científicos, sem qualquer identificação de indivíduos.

Qualquer possibilidade de identificação que porventura ocorra durante a coleta de informações será adaptada no sentido de preservar o sigilo do participante. Entretanto, dependendo do nível hierárquico e/ou da função desempenhada, não se poderá garantir que sua identificação não seja deduzida ou revelada por leitores, em momento posterior ao término do trabalho, especialmente durante a publicação dos resultados alcançados.

\subsection{Análise de dados}

Será feita análise dos dados na perspectiva hermenêutico-dialética, tendo como base o Estatuto da Criança e do Adolescente e os quatro princípios da Bioética Principialista: o respeito à autonomia, a beneficência, a não maleficência e a justiça, tendo os dois primeiros caráter teleológico e os dois últimos deontológicos (Beauchamp, 1979, p. 20).

Neste sentido, a entrevista seguirá um roteiro contendo tópicos referentes ao dever do Estado na educação, à competência e à autonomia da família para o ensino domiciliar e ao desenvolvimento e socialização da criança. Desde o início e no decorrer do estudo, será realizada a análise dos dados textuais oriundos das transcrições de acordo com princípios hermenêutico-dialéticos balizados por Minayo (2013, p. 22-25) e com o apoio do software webQDA de análise qualitativa de dados (Costa, \& Amado, 2018, p. 2-10).

Após leitura e releitura dos textos, será identificado o conteúdo mais relevante por meio da observação das semelhanças, divergências e contradições nas narrativas. Os dados serão codificados no webQDA após identificação do que houver de comum nas narrativas. Serão utilizados como base teórica de análise os princípios da Bioética Principialista. Buscam-se identificar os sentidos atribuídos pelos sujeitos à questão levantada, para entender a lógica 
interna desse grupo, em diálogo comparativo com a literatura. Ao final, será elaborada uma síntese interpretativa com vistas a responder o questionamento do estudo.

\section{CONCLUSÕES PROVISÓRIAS}

Como a legislação é omissa em relação à permissão do ensino domiciliar, as opiniões científicas sobre esse tipo de ensino são importantes para se chegar às conclusões finais dos benefícios, malefícios, autonomia da vontade e justiça em relação ao homeschooling no Brasil, uma vez que em outros países tal modalidade já é permitida.

Os educadores que trabalham e pesquisam junto aos programas de pós-graduação strito sensu, ou seja, que lidam cotidianamente com esta matéria, oferecem suas opiniões como produto de investigação e não como opiniões pessoais imbuídas de valores morais, jurídicos, religiosos e éticos.

A matrícula na rede regular de ensino é quase sempre combatida por aquelas famílias que praticam o ensino domiciliar, alegando que a obrigatoriedade seja para as famílias que não conseguem prover a educação por falta de recursos, ou por quererem exercer a liberdade de ensinar e aprender, nos termos da Constituição Federal.

A opinião dos adeptos ao ensino domiciliar é no sentido de existir alternativa para a ampliação da integração da família com a escola e vice-versa, partindo da responsabilidade comum a ambos, como está previsto no artigo 205 da Carta Magna.

Tal situação permite constatar o fato de se viver uma época em que há pouca motivação quanto aos aspectos relativos à moralidade, seja secular ou religiosa, conforme questionam os autores: "Afinal, por que se deveria agir com justiça se isso não vai nem ajudar nos próprios planos de vida da pessoa (às vezes podendo até ameaçar estes planos), nem levar ao paraíso?" (Serodio, Kopelman, \& Bataglia, 2016, p. 238).

\section{REFERÊNCIAS}

Ariès, P. (1981). História Social da Criança e da Família. 2. ed. Tradução de Dora Flaksman. Rio de Janeiro: Guanabara.

Beauchamp, T. L. (1979). Principles of Biomedical Ethics. Oxford: Oxford University Press, 1979.

Borges, C. J. P. (2019). Perspectivas educacionais em revista: explorando as interfaces da educação social. Disponível em: <http://www.proceedings.scielo.br/pdf/cips/n3/n3a02.pdf>. Acesso em: 29 nov. 2019.Brasil (2020). Constituição da República Federativa do Brasil. Texto constitucional promulgado em 5 de outubro 
de 1988, compilado até a Emenda Constitucional n 106/2020. Brasília: Senado Federal.

Brasil (2019). Estatuto da Criança e do Adolescente. Lei n 8.069, de 13 de julho de 1990. Brasília: Câmara dos Deputados.

Costa, A. P., \& Amado, J. (2018). A análise de conteúdo suportada por software. Aveiro: Ludomedia.

Diniz, D., \& Guilhem, D. (2012). O que é Bioética? São Paulo: Brasiliense.

Gavassi, S. L. Os desafios da escola pública paranaense na perspectiva do professor. In: O Impacto do Estatuto da Criança e do Adolescente-ECA na Escola (1990-2015): um estudo de caso. Cadernos PDE. Disponível em: <http://www.diaadiaeducacao.pr.gov.br/portals/cadernospde/ pdebusca/producoes_pde/2014/2014_unespar/paranavai_hist_artigo_susana_lisboa_gavassi.pdf >. Acesso em: 24 nov. 2019.

Halpner R. Teorias e características do desenvolvimento da criança. In: Halpner R. (2015). Desenvolvimento e comportamento. São Paulo: Manole, 1-14.

Heywood, C. (2004). Uma história da infância. Tradução de Roberto Cataldo Costa. Porto Alegre: Artmed.

Minayo, M. C. S. (2013). O desafio do conhecimento: pesquisa qualitativa em saúde. 13. ed. São Paulo: Hucitec.

Pereira, A. T. (2020). A relação entre o direito e a bioética. Disponível em:

<https://ambitojuridico.com.br/edicoes/revista-45/a-relacao-entre-o-direito-e-a-bioetica/>. Acesso em: 19 abr. 2020.

Perez, J. R. R., \& Passone, E. F. (2010). Políticas sociais de atendimento às crianças e aos adolescentes no Brasil. Cadernos de Pesquisa, 140 (40), 649-673.

Sá, E. (1998). Biodireito: inter-relações do Direito e das Ciências Biomédicas. Rio de Janeiro: CEJUR - DP.

Serodio, A., Kopelman, B. I., \& Bataglia, P. U. R. (2016). A promoção das competências moral e democrática: por uma virada educacional da Bioética. Revista Bioética, 24 (2), 235-242. 